\title{
Analysis of Debussy Piano Music "Fireworks" Performance
}

\author{
Junzhong Zhang \\ The Music Department in Teachers College of Eastern Liaoning University
}

\begin{abstract}
Debussy is one of the famous composers in music history, and he not only created a lot of innovative music, but also created a musical impressionist era, it is a landmark composers having. "Fireworks" is one of the important works of Debussy, which was the last song he composed 24 piano preludes, and this work fully reflects all his creative ideas, creative approach and creative style, as well as their patriotism inner world monologue. This paper focuses on the piano Debussy's 24 Preludes a brief introduction, analyze the reasons for the formation of its style and structure of the work through, music image, sound system and playing tips and other aspects of "fireworks".
\end{abstract}

Keywords-Debussy; Piano Preludes; Performance analysis; Fireworks Impressionism

Debussy, all Mingkeluode • Debussy, (Clande Achill Debussy), living in the nineteenth century, early twentieth century, is a very influential composer of the European music industry, he is also the most respectable musician in twentieth century. In his life he not only created a lot of innovative music, a landmark in the history of music, but also he is the originator of the modern impressionist music. Debussy extensively use music and Impressionist painting the same aesthetic principles, emphasize the individual's subjective feelings and transient changes of light and color, his representative of "Prelude Afternoon of a Faun," piano "Prelude" and "Practice song "and where" Perry Elias and Merry Sander "is the highest peak of their musical creations. During World War I, he also wrote a number of works about the suffering of the people, his work can be said to be one depictive Impressionist picture with the music, therefore, he can be classified as a musicologist Impressionist composers, he was known as the founder of Impressionist music and has a very profound impact on the development and progress of European music.

\section{Introduction About 24 Debussy Piano Preludes}

Prelude is an ancient music genre, in the very beginning it is with a primer characteristic, it is introducing the topic and services, structural short, and it is a kind of prologuestyle improvisation, playing instrumental music for organ or lute. To the seventeenth century, composers of the Baroque period will be the prelude to this early inheritance and development to become the beginning of the song suite or Fugue. After the nineteenth century, it gradually developed into a prelude to the independence of the piano repertoire appearing on the music scene, such as Chopin's "Prelude twenty-four" is the famous piano prelude music. With the development and changes in the piano music, the prelude of its novelty and material selection of musical language in the form of extensive musicologist is widely loved, it contains ancient legends and myths, as well as portraits description, and content compliment the natural scenery and other aspects of [1]. Debussy's "twenty-four Piano Prelude", are divided into the first episode and the second episode, each episode has a twelve, twenty four Preludes are for its poetic title, it has varied colors and sound perfect combination with the poetic, it is full of charm and aesthetic appeal, vividly reflecting his Impressionist aesthetic principles, this piece of music not only embodies the essence of musical works as Debussy, but also makes this prelude the creation reach a peak of historical development in the genre.

\section{Debussy Piano Preludes "FiREWORKS" Style FORMATION AND HISTORICAL BACKGROUND}

Debussy was born in a family of farmers, although there is no good music environment, but he is passionate about music since childhood, and revealed significant musical talent. During his music the learning process, he is very innovative, and eager to explore new areas, break stereotypes, to seek new ways of musical expression. His piano music style is greatly affected by the prevailing spirit of the French national art and aesthetic ideas, aesthetic ideology combines aesthetic principles Impressionist painting and Symbolist poetry, it formed its own unique style of writing, and playing style. Impressionist paintings emphasize the beauty of light and color in the transformation of artistic expression, focus on the outstanding performance of the creators of the moment to capture the visual experience, but the symbolism is even more emphasized by the suggestion of poetry and symbolism of things and feelings expressed [2 ]. Under the influence of Debussy both aesthetic thought, he formed a focus on the creation of national character art style, inherited the seventeenth century harpsichord school Karma's too elegant, gentle and lyrical way and colorful art style in the creation, and broke Romantic musical tradition of "love" for the United States the principle of nature scenes with praise. Its music tactfully whisper quiet gentle, and shows a very rich expressive power in the details.

\section{ANALYSIS OF DEBUSSY PiANO MUSIC "FIREWORKS" PERFORMANCE}

"Fireworks" is most ornate and colorful works of twenty-four Prelude, in this period Debussy creative concept has matured, their music not only embodies the essence of Debussy's musical language, but also is into the a 
lot of abstruse and gorgeous skills. World War II was approaching, more and more rich smell of gunpowder is on the battlefield, patriotism Debussy had also been unprecedented inspired the song "fireworks" in many places a "La Marseillaise," the tone, through various intervals combination of arpeggios, chords, scales, touch keys, as well as changing the color of the evening sound, color, light, atmosphere rich and delicate depiction shows us the square in Paris during a grand festival fireworks celebration discharge fireworks scene, suggesting the fireworks banquet in warm, festive, jubilant scenes. Debussy's use color as a master, through his subtle way and musical language, the use of vague outline brought sound, hazy color and hue change is not easy to distinguish, and it guides people through hearing to create a colorful and have sound visual illusion, by stimulating the audience's imagination, he constitutes a unique musical language of Debussy with high aesthetic realm. This not only reflects the Debussy Preludes patriotism, but also reflects the Frenchman's elegant and romantic. Let us fully appreciate the piano music of Debussy unique artistic charm.

\section{A. Analysis of Debussy Piano Music "fireworks" works}

1) Structural analysis of Debussy Piano Music "fireworks". "Fireworks" uses Liberal style song structure in the creation, combined with rondo-like structure, with a single image and structure which makes it a short prelude to the first large-scale. The whole song structures with Debussy's impressionistic style of music features are divided into seven parts: A-- transition --B - C - D - E-- end [3]. Part A total of 18 small sections is occupied a relatively large space in the whole song in. Transition from the second syllable of the first 18 to 24 bar section begins, the expression is used in fast toccata style, with Part A and Part B in stark contrast. Part B is 25 to 26 bar, the main feature of this section is to scale smooth. Part $C$ for $47-56$ sections echoed the previous transition, but also plays a role in the transition connection, this feature is to use part of the column chord, so that the music has a contrast. Part D is 5770 sections use broken chords type of music the way to undertake a musical atmosphere, in Part B of this section, figurations are very soft, smooth, creative approach on Part $\mathrm{B}$ is also echoed. Part E has 71-87 sections, in this section, "La Marseillaise," the theme of tone appeared in large numbers, musical detail changes, more and more enthusiastic mood music ultimately achieve orgasm. 88 bar and 89 bar entry into the end of the transition, the end part is the 90 sections to 98 sections, with remote and quiet melody the song ends.

2) Image analysis of Debussy Piano Music "fireworks" music. Debussy Preludes title and Romantic music title is different, impressionistic title only gives a vague hint, rather than makes people produce specific emotional experience and Lenovo. Debussy wrote at the end of the song and will be back at the brackets, indicating that this is not the title of
Debussy's music seems real, but he wants to provide the title of the atmosphere [4]. In the "fireworks" in this song, the music of Debussy impression is characteristic of Impressionism and Symbolist poets are together to produce, he will organically blend a variety of impressionist music, creative approach, not only for fireworks color, light, sound, which have carried on the evening vivid descriptions, and even the mood of the people at the party were delicate performance, which creates a rich musical image, and greatly stimulate the generation of visual illusion caused by hearing. First, the "fireworks" with minor second interval is throughout the whole song, for the people at the party and fireworks joy are intertwined with scenes of jubilation for detailed description, with a short piece of motivation the audience left rich imagination. Secondly, the Heijian pentatonic is effective into the whole song diatonic, giving the music a visual illusion of infinite, as if to see the fireworks constantly changing rainbow colors. Once again, the second time the occasional loud part octave sound is like little stars in the night sky, with a strong scratch-outs from top to bottom across six octaves, which is like a meteor across the quiet night sky, people fascinated. Finally, the whole song is like a very faint melody of the French national anthem church bells finishing, fully embodies the patriotic fervor of the heart surging, it echoes with the beginning of the song, and highlights the song's theme [5].

3 )Harmony System Analysis of Debussy Piano Music "fireworks". The main purpose of the use of harmonies of Debussy piano works is the quest for color variability, "fireworks" is the typical use of color and sound. Debussy makes music to take on the position of double or single use, and the way the use of the mutual integration of the natural size tuning, Eastern pentatonic scale, there are some vague tone tonality, etc., by the climax of "harmony compounds" practices to meet the needs of color music image, music titles in atmosphere rendering are integrated into the various tonal colors and bright to go into, and there is no swapping of stiffness. Debussy's harmonies come from the acoustics inside the extended knowledge of nature, so it uses way more freedom and unrestricted [6]. For example, there are nine inversions decomposition at 25-29 sections, large and small, diminished chords and the second interval intensive paralleling with the sounds which needed to shape the image of the typical music and "massive harmony."

\section{B. Analysis of Debussy Piano Music "fireworks" Performance}

In Debussy Preludes "fireworks" of creation, in addition to the pursuit of unique colors and harmonies, perfect performance on the piano playing skills also opened up a new path. Debussy piano inherent in the study of the great achievements of the sound, he does not advocate simply expand the volume of the magnitude of the piano, but 
advocates try to dig hierarchy within the pianissimo range. "Fireworks" is not as spectacular as other works of splendid momentum, although there are brief strong, with explosive sound climax, but they are very short, which gives players forward higher requirements in the control of the sound [7]. All kinds of color is extremely massive harmonies when playing in a weak sense of finger stick to support key, then it is key in the natural means of arm strength to sink, so as to play the weak and not imaginary floating tone, when strong playing have explosive. Using pedal is one of Debussy innovation performance in the "fireworks" in the whole song and it does not appear in a pedal mark, so players are difficult to grasp its rhythm. For example, in the 53-54 section he marked "1aissez vibrer" (let it shake sounding) term in pianissimo D sound on bass, it requires players to use the damper pedal while also using the soft pedal , it is possible to make the sharp contrast in front and rear of the tone and volume [8].

\section{SUMMARY}

Claude Debussy is an outstanding history of piano music, music creators landmark in Europe, in the creation of his early works, the traditional approach in the creation of awareness is with the Impressionist style, after under the influence of the impression painting of Symbolist poets, his creative style gradually developed, and ultimately play the creation of the Impressionist style to an extreme, and he works for the development and progress of the world of music and has made tremendous contributions. His works are unique, very innovative, and "twenty-four Piano Prelude" is that he embodies the idea of the creation of later musicians' creative thinking and creative ideas which have had a great impact [9]. "Fireworks" is the longest Debussy piano works in a song, it will concentrate Debussy music styles (conjoined musical form and 3D music) with its clever fusion of patriotic ideas together, he created a first immortal chapter breaking all music systems way of thinking, this work of art with its unique and exquisite impression creative skills become a model for Debussy's music, and it reflects Debussy's patriotic enthusiasm, and also a microcosm of the creative spirit of his life.

\section{REFERENCES}

[1] Deng Kun. Debussy Piano Preludes "Fireworks" music and performance analysis [J] music .2009 (11): 80-81

[2] Mei Yang. Debussy piano preludes and playing music feature points [J] artistic exploration 2009 (03): 75-76

[3] Wu Yumin. How to play Debussy's piano Preludes "fireworks" [J] big stage .2011 (10): 20-20

[4] Shi Xia. On the Debussy piano preludes Xia "fireworks" Performance [J] Jilin College of Education (mid) .2012 (03): 15-16

[5] Chen Shi. Proper analysis of Debussy's life and creative style [J] Northeast Electric Power University (Social Sciences Edition) 2009 (05): 53-54

[6] Sun Jing. Colorful world of light and shadow - Analysis of Debussy Preludes "fireworks" [J] Zaozhuang College .2010 (06): 32-33.

[7] Lin Biejia. Debussy Piano Preludes "fireworks" teaching analysis [J] Art Gallery .2011 (11): 19-20

[8] Tan XiYu. Talk about patriotism impression Debussy piano works "fireworks" [J] Popular Literature .2013 (02): 13-15

[9] Zhao Yan. dream and implied - Works from the impressionist colors of Debussy orchestral language style formation [J] Popular Literature (theory) .2009 (21): 37-37. 